\title{
Role of medical therapy in critical coronary disease, a single center experience
}

\author{
Igor Šesto*, \\ Krešimir Štambuk, \\ Hrvoje Stipić, \\ Tomislav Šipić, \\ Ante-Zvonimir Korda, \\ Igor Alfirević, \\ Davor Richter, \\ Janko Szavits Nossan, \\ Goran Milašin, \\ Mihajlo Šesto
}

Magdalena Clinic for Cardiovascular Disease, Medical School, University J. J. Strossmayer in Osijek, Krapinske Toplice, Croatia

RECEIVED:

September 15, 2015

ACCEPTED:

September 17, 2015

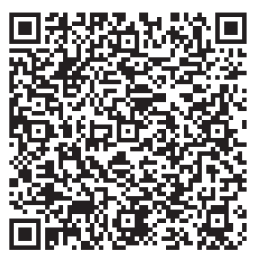

口 Cardiologia Croatica 2015;10(9-10):240.
KEYWORDS: coronary artery disease, conservative treatment, inoperable.

CITATION: Cardiol Croat. 2015;10(9-10):240. | DOI: http://dx.doi.org/10.15836/ccar.2015.240

*ADDRESS FOR CORRESPONDENCE: Igor Šesto, Klinika za kardiovaskularne bolesti Magdalena, Ljudevita Gaja 2, HR-49217 Krapinske Toplice, Croatia. / Phone: +385-98-358883 / E-mail: igor600@me.com

ORCID: Igor Šesto, http://orcid.org/0000-0002-2201-4425

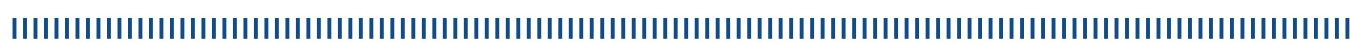

In our hospital cardio-surgical medical council has over time developed into a genuine heart-team jointly and equally discussing the best possible treatment strategies in patients displayed.

What we found interesting to see is what happened to the patients suffering from critical coronary artery disease for whom were on our cardio-surgical council further conservative treatment indicated.

The study included all patients with coronary artery disease (no of patients $=85$ ) who were in the last five years presented on our cardio-surgical council, for whom we gave up on any active revascularization strategy (percutaneous coronary intervention or coronary artery bypass graft surgery), and conservative treatment was indicated.

Further more included were only patients who were not operable (coronary artery bypass graft surgery) due to anatomical and pathological constellation on their coronary arteries, and percutaneous revascularization was not possible because of extremely high risk of the procedure itself, or intervention was not technically feasible.

Inclusion and exclusion criteria were as follows: significant left anterior descending artery disease, the absence of significant valvular disease, the absence of significant comorbidities that could lead to the shortening of life expectancy.

Retrospective analysis of collected data, included 85 patients who were shown to our cardio-surgical council in last 5 years, we made a telephone follow-up, which found an mortality of $9.8 \%, 15.3 \%$ of patients were re-hospitalized because of persistent symptoms of coronary artery disease. Only 2 patients subsequently underwent surgical revascularization, none of the patients received further percutaneous revascularization.

The results obtained show that in advanced coronary artery disease, which is technically not suitable for any form of revascularization, optimal medical therapy is a feasible treatment strategy. ${ }^{1,2}$

LITERATURE IIIIIIIIIIIIIIIIIIIIIIIIIIIIIIIIIIIIIIIIIIIIIIIIIIIIIIIIIIIIIIIIIIIIIIIIIIIIIIIIIIIIIIIIIIIIIIIIIIIIIIIIII

1. Murphy ML, Hultgren HN, Detre K, Thomasen J, Takaro T, and Participants of the Veterans Administration Cooperative Study. Treatment of chronic stable angina, a preliminary report of survival data of the randomised Veterans Administration Cooperative study. N Engl J Med 1977;297:621-7. DOI: http://dx.doi.org/10.1056/NEJM197709222971201

2. Park DW, Yun SC, Lee SW, Kim YH, Lee CW, Hong MK, et al. Long-term mortality after percutaneous coronary intervention with drug-eluting stent implantation versus coronary artery bypass surgery for treatment of multi vessel coronary artery disease. Circulation. 2008;117(16):2079-86. DOI: http://dx.doi.org/10.1161/CIRCULATIONAHA.107.750109 